\title{
BEHAVIOR OF PHARMACEUTICALS IN EFFLUENT WATER: SAIDAL GROUP (CONSTANTINE ALGERIA)
}

\author{
C. Saouli* and R. Assabaa \\ Laboratory Rehabilitation of ecosystems and sustainable development (REDD), Mentouri \\ brothers university of Constantine, Algeria \\ *E-mail: saouli.chouaib@umc.edu.dz
}

\begin{abstract}
Measured concentrations for selected pharmaceuticals in effluent water of SAIDAL group located in the city of Constantine (Algeria), it was found that the efficacy of these predictions varied and was hampered by a shortage of data for many of the drugs. Oxcyladine citrate, Nepagine and Salbutamol were detected and quantified in all locations sampled, Nepagine was consistently found at the highest centration $4.7 \mathrm{ppm}$, levels up and downstream of tow wastewater treatment works were compared in order to investigate the link between sewage discharge and environmental concentrations of pharmaceuticals. Monitoring studies, using born as wastewater tracer grave information conceding seasonal variation of degradation phenomena in natural waters and partition phenomena accruing between dissolved and solid phases.
\end{abstract}

Keywords: pharmaceuticals, predictions, pollution, wastewater.

(C) RASĀYAN. All rights reserved

\section{INTRODUCTION}

Water is an essential component of most major processors of food products of animal origin. After being used, the largest part of the process effluent is returned to the environment. As this water is usually loaded with organic matter, it becomes an important source of pollution to the surroundings who receives it.

The SAIDAL group manufactures pharmaceutical and syrup of insulin, the behavior of insulin is of amino acids and the behavior of syrup it's more like molecule alertine, bromehexine, $\mathrm{HCl}$, encofluide adult, oxyladine sitrate, and salbutamol valcine. It is for that finds of them several molecules in water-worn by this group, responsible for the physicochemical and bacteriological quality of industrial wastewater group (SAIDAL). Several studies have interested by characterization and treatment of this type of wastewater through treatment plants or by aerobic processes ${ }^{1-3}$. Either by anaerobic processes ${ }^{4-7}$. Other methods of treatment are adopted for sewage namely sand infiltration ${ }^{8-9}$ and electrocoagulation ${ }^{10-11}$.

During the 1990s, pharmaceutical compounds, such as analgesics, lipid-lowering drugs and hormones were detected in waste waters across Europe ${ }^{1-2}$, and the USA ${ }^{3-4}$. Though concentrations of pharmaceuticals detected in drinking water are several orders of inferior magnitude than the minimum therapeutic dose ${ }^{5}$.

While concentrations are generally found to be in the $(\mathrm{ng}-\mu \mathrm{g}) \mathrm{L}^{-1}$ range, well below the levels thought to be acutely toxic to humans, several reviews dealing with the occurrence, fate and effects of pharmaceuticals in the environment are available ${ }^{8-9}$, and show the main influence of sewage treatment plant discharges on the contamination of aquatic systems. A great deal of work has been down recently to identify and quantify organic contaminant traces in waste water treatment plant (WWTP) effluent, there are a number of different options available for the treatment and management of waste containing dodging, mitigation re-use, reutilizing, energy recovery and disposal ${ }^{10}$. This study examines the behavior of compounds belonging to several chemical and therapeutic groups, salbutamol, oxyladine cetrate, Nepagine. These compounds have been measured in a waste water effluent of the SAIDAL group situated on a littoral of the RHUMELES River in Constantine department of Algeria, highly impacted by a waste water treatment plant effluent.

Rasayan J. Chem., 11(3), 951-954(2018)

http://dx.doi.org/10.31788/RJC.2018.1133008

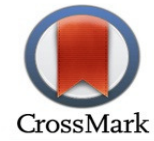


RASĀYAN $J$. Chem.

Vol. 11 | No. 3 |951 - 954 | July - September | 2018

This study site is subject of our researches since the year of 2010; in the first step we evaluate the physicochemical parameters of wastewater group SAIDAL ${ }^{11}$ and in second is the work which we will present in this paper.

\section{EXPERIMENTAL}

The measurements based on RP-HPLC method, which can quantify the components simultaneously from a combined dosage form ${ }^{12}$. The preparation of wastewater sample and experimental diagram are performed in the laboratory of SAIDAL Groups. The chromatograms were recorded and the peak areas of Nepagine, Salbutamol and Oxyladine cetrate were determined, the calibration curves relating peak areas to the corresponding concentrations were constructed for the three compounds and the regression equations were computed. The precision of this method was checked by the repeatability of injection, repeatability intermediate precision and reproducibility. Peak areas and retention times obtained by determining six replicates of a fixed amount of drug ${ }^{13}$.

\section{RESULTS AND DISCUSSION}

The experimental results are shown in (Figure-1, 2 and 3). These curves present the chromatogram of pharmaceutical substances to detect (Nepagine, Salbutamol, Oxyladine cetrate), and for each pharmaceutical substances, we present a standard chromatogram (Figure 1.a and 2.b) to calculate the substances concentration. But in the cases of not exiting of the peak detection of substance to detect, thus we do not need to calculate the substance concentration and we do not present the standard chromatogram, it's the case of Salbutamol (Figure 3). The substance concentration calculated from the equation blow:

$\mathrm{C}=($ test Area $/$ standard Area $) \times$ TSTD $\times$ Constant $\times$ PSTD.

Where: $\mathrm{TSTD}=99.3 \%, \mathrm{PSTD}=50 \mathrm{mg}$ and Constant $=0.000025$.

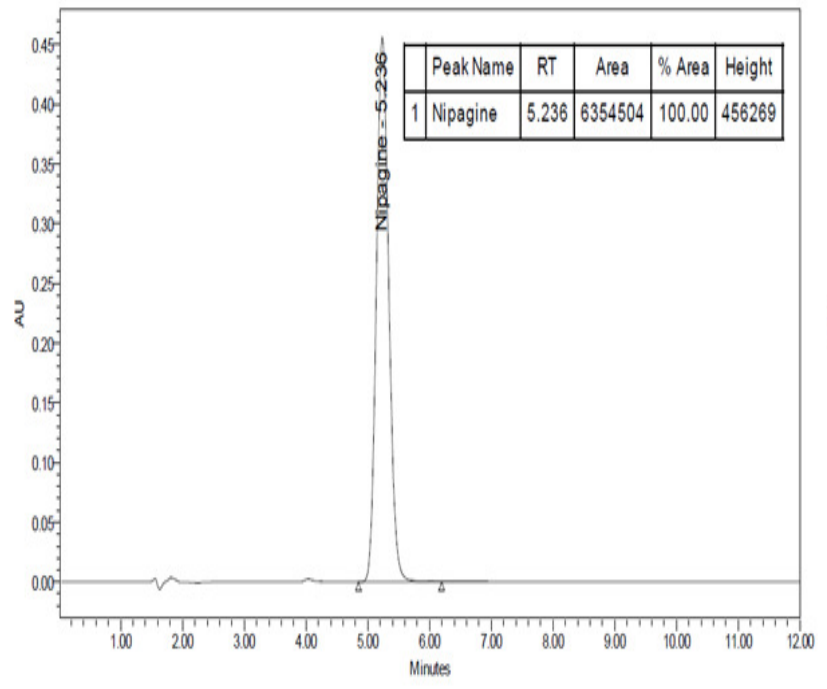

(a)

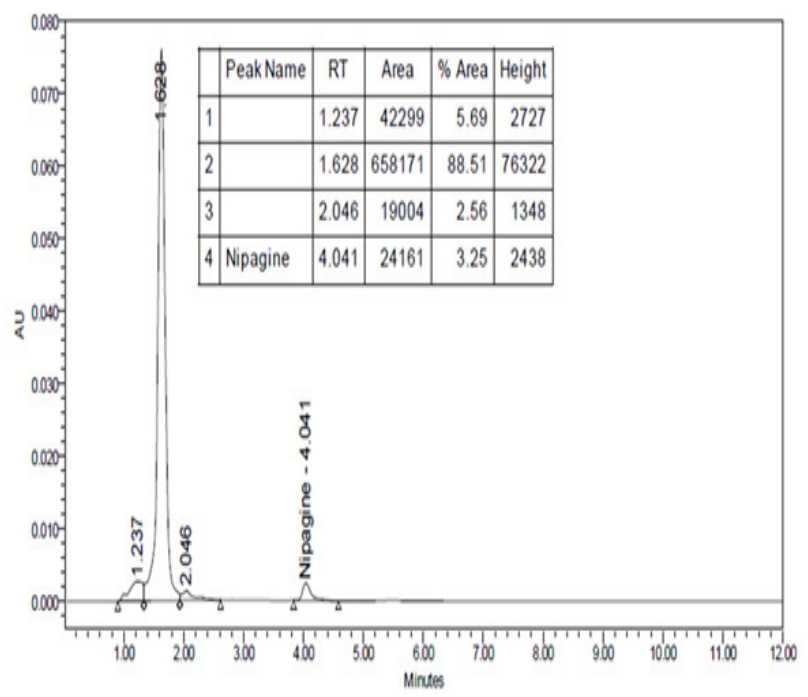

(b)

Fig.-1: Chromatograms: (a) for the standard of Nipagine, (b) for the determination of Nipagine in the evacuation waters of the SAIDAL group

The predicted and concentration calculation was carried out for the tri selected pharmaceuticals based on data from the SAIDAL group producer of pharmaceuticals (Figure-1, 2 and 3) shown in (Table-1).

The assessment for Salbutamol would stop evacuation as the predicted and measured concentration is below the threshold of $0.01 \mu \mathrm{gL}^{-1}$ stipulated by the EMEA. Nepagine was consistently found in the highest concentration $4.7 \mu \mathrm{g} . \mathrm{L}^{-1}$, Salbutamol $0 \mu \mathrm{g} . \mathrm{L}^{-1}$, oxeladine citrate $0 \mu \mathrm{g} . \mathrm{L}^{-1}$. The finding of pharmaceuticals before the influence of this WWTW. The contamination levels in the "waste water of group SAIDAL" depending drug production capacity. So that, the concentration decreases were only due to the dilution factor without any kind of degradation, weather conditions did not favor photo-degradation 
and biodegrading and shorter transit time decreased decay rates all along the studied area. By considering the dissolved agonic carbon content, the influence of the WWTP discharge deceased all along the River with dilution and degradation phenomena. The increase for the last simples corresponds to the influence of the RHUMELES River situated in the city of Constantine; this River is under the influence of dynamic tides and contains high suspended particulate matter concentration ${ }^{14}$.

Table-1: The Concentration of Pharmaceutical Substances in Waste Water Effluent of the SAIDAL Group.

\begin{tabular}{c|c}
\hline Pharmaceutical substance & Concentration $(\mathrm{ppm})$ \\
\hline Nepagine & 4.7 \\
\hline Oxeladine citrate & 0 \\
\hline Salbutamol & 0 \\
\hline
\end{tabular}

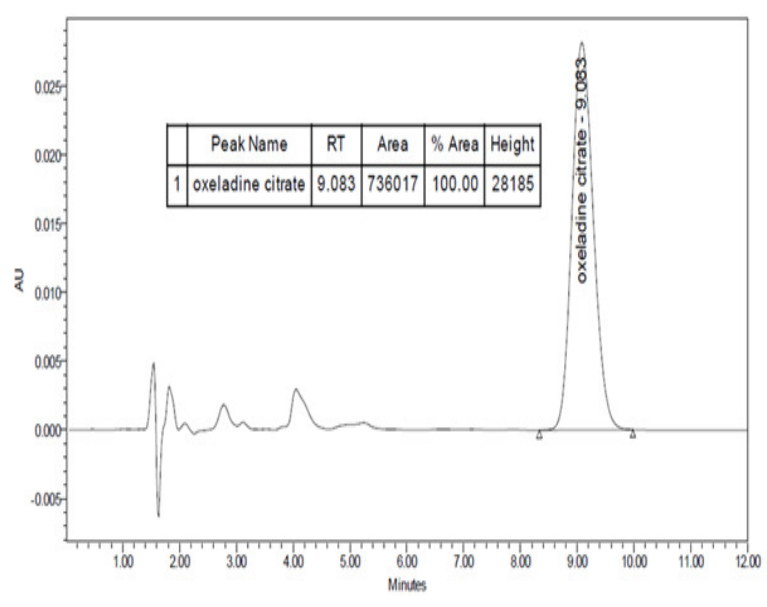

(a)

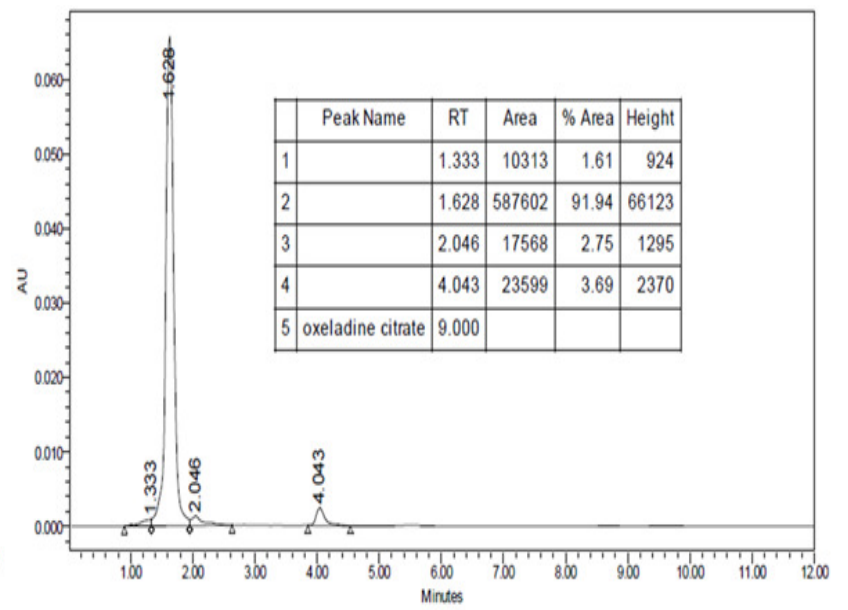

(b)

Fig.-2: Chromatograms: (a) for the standard of Oxeladine citrate, (b) for the determination of Oxeladine citrate in the evacuation waters of the SAIDAL group

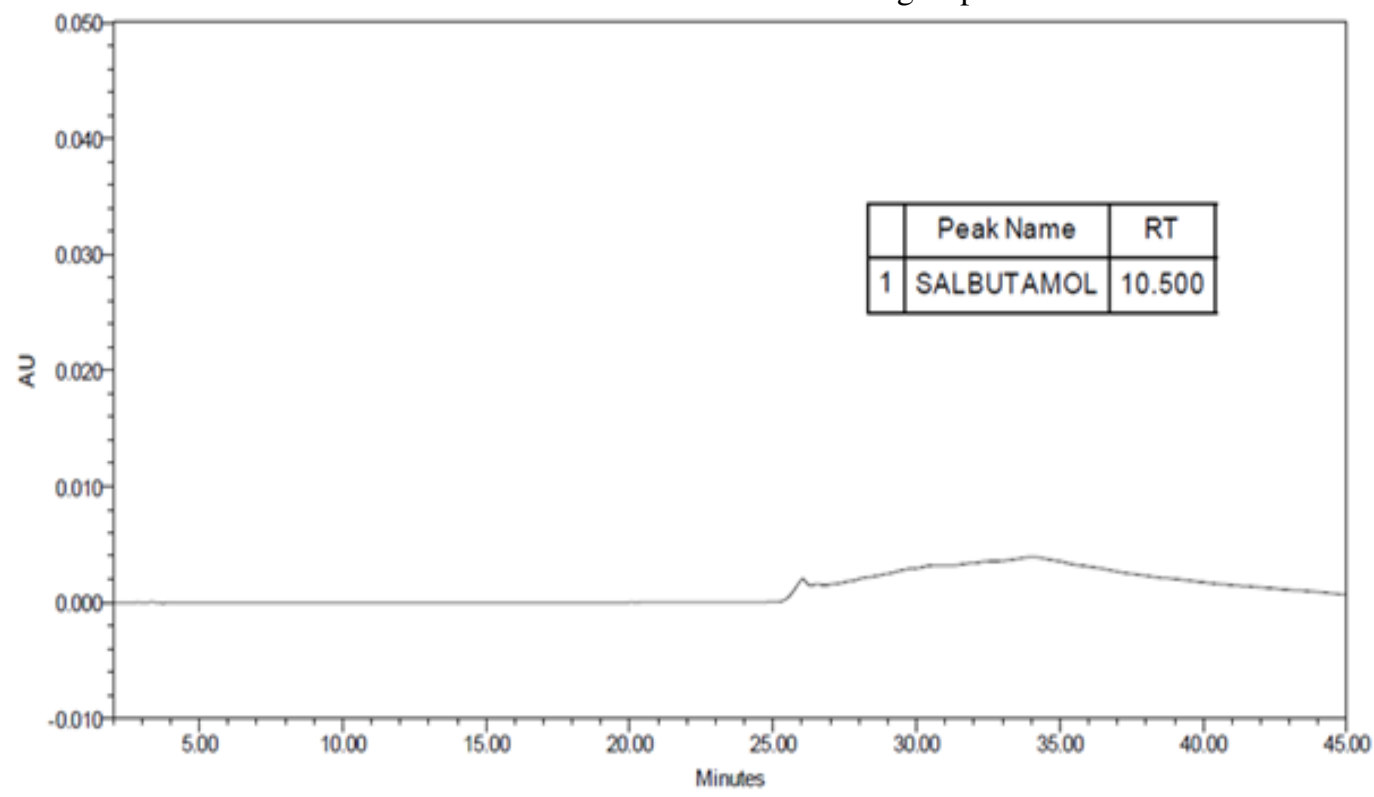

Fig.-3: Chromatograms for the determination of Salbutamol in the evacuation waters of the SAIDAL group.

\section{CONCLUSION}

This study has allowed a better understanding of the behavior of drugs after their introduction to the aquatic system. Pharmaceuticals have been quantified both in dissolved and particulate phrases at high 
RASĀYAN J. Chem.

Vol. 11 | No. 3 |951 - 954 | July - September | 2018

concentration levels, that allow obtaining new data concerning pharmaceutical partition. The monitoring of this compound all along a River in different climatic conditions has given us much information concerning the fate of pharmaceuticals in aquatic systems after their introduction. Thus, the main part played by photo-degradation during degradation phenomena has been highlighted. This study has used born as an anthropic effluent maker and has proved that is a strong tool, when WWTP discharges have been correctly identified and if the natural introduction of born in the aquatic system occurs.

The existence of pharmaceutical substances such as Nepagine with $4.7 \mathrm{ppm}$, and Oxeladine citrate and salbutamol with variable concentrations in the effluent of SAIDAL group can impact in the environment, especially the location of group SAIDAL in the next to the RHUMELES River where traverse the middle of Constantine city. So, the chemical treatment of wastewater of effluent of SAIDAL group is an obligation with the measure of the concentrations of pharmaceutical substances before and after the treatment of wastewater.

\section{REFERENCES}

1. T. Hoverer, Toxicol. Lett., 131, 5 (2002), DOI: 10.1016/S0378-4274(02)00041-3

2. T. A. A. Terns, Trends in Analytical Chemistry, 20, 419(2001), DOI: 10.1016/S01659936(01)00078-4

3. G. R. Boyd, M. Reemtsma, et al, Sci. Total Environ., 311,135(2003), DOI :10.1016/S00489697(03)00138-4

4. D. W. Kolpin, M. Skopec et al, Sci. Total Environ., 328, 119(2004), DOI : 10.1016/j.scitotenv.2004.01.015

5. Expert Committee on Food Additives (JECFA), World Health Organization, Geneva, 69, 250 (2014).

6. A. Sk. Heerah, A. Mudhoo, R. Mohee and S. K. Sharma, Rasayan J. Chem., 1(3), 503 (2008).

7. P. Sharma, L. Singh and J. Mehta, Rasayan J. Chem., 3(4), 731(2010).

8. H. D. Hernando, M. Me Zcua, et al, Talanta, 69, 334 (2006), DOI: 10.1016/j.talanta.2005.09.037

9. B. Halling Sorenson, S.N. Nielsen, et al, Chemosphere, 36, 357 (1998), DOI: 10.1016/S00456535(97)00354-8

10. K.R. Mahadik, M.B. Sarda, Pharma Times, 48, (2016).

11. C. Saouli and R. Assabaa, Rasayan J. Chem., 10(4), 1439 (2017), DOI: 10.7324/RJC.2017.1041821

12. R. Kalirajan, K. Anandarajagopala, et al, Rasayan J. Chem., 1(2), 232 (2008).

13. J. Debata, S. Kumar et al, Int J Drug Dev \& Res, 9, 48 (2017).

14. G. Abril, M.V. Commariew, et al, Geophys. Res. Lett., 31, 1 (2004), DOI: 10.1029/2004GL019714

[RJC-3008/2018] 